\title{
Teaching Science Students How to Think
}

\author{
Bonnie McBain ${ }^{\mathrm{a}}$, Andrew Yardy ${ }^{\mathrm{d}}$, Frances Martin ${ }^{\mathrm{b}}$, Liam Phelan ${ }^{\mathrm{a}}$, Ian van Altena ${ }^{\mathrm{a}}$, \\ Jill McKeowen ${ }^{\mathrm{d}}$, Claire Pemberton ${ }^{\mathrm{d}}$, Hollie Tose ${ }^{\mathrm{c}}$, Lindsey Fratus ${ }^{\mathrm{e}}$, Michael Bowyer ${ }^{\mathrm{a}}$. \\ Corresponding Author: Bonnie McBain (bonnie.mcbain@newcastle.edu.au) \\ ${ }^{a}$ School of Environmental and Life Sciences, The University of Newcastle, Australia \\ ${ }^{b}$ School of Psychology, The University of Newcastle, Australia \\ ${ }^{c}$ Faculty of Science, The University of Newcastle, Australia \\ ${ }^{\mathrm{d}}$ Centre for Teaching \& Learning, The University of Newcastle, Australia \\ eUniversity Library Academic Division, The University of Newcastle, Australia
}

\begin{abstract}
Scientific thinking is more than just critical thinking. Teaching the full range of ways to think like a scientist who practices high quality science is rare. A new core subject in the Bachelor of Science at the University of Newcastle was developed to allow students to explore six different ways to thinking scientifically through understanding what high-quality science is and contrasting it with poor science and non-science (pseudoscience). Our evaluation indicates that learning about how to think scientifically and be a scientist who practices high quality science is a skill that is valued by and relevant to first year undergraduate students. An evidence-based pedagogy including active learning, participatory learning, student-centred learning, constructive alignment and quality formative and summative feedback to students can support high learning outcomes.
\end{abstract}

Keywords: scientific thinking, active learning, pseudoscience, scientific literacy

\section{Introduction}

\section{Scientific thinking in science education}

There is significant focus on the value of teaching critical thinking skills in science (for example, Rowe et al., 2015; Zimbardi, Bugarcic, Colthorpe, Good, \& Lluka, 2013). Critical thinking skills underpin scientific literacy and the quality of decision making. However, critical thinking is just one thinking skill required by scientists. In an increasingly complex world that requires solutions to wicked problems (Rittel \& Webber, 1973) we need innovative ways to address these problems.

Causal thinking or reasoning is implicit in critical thinking. We use different approaches to apply causal logic (inductive, deductive, abductive etc.) to make sense of evidence and multiple sources of information (Dunbar \& Fugelsang, 2005). Being aware of which causal reasoning we can use allows us to be much more systematic in how we reason and learn (Lagnado, 2011).

The process of scientific discovery also requires creative thinking just as much as it requires critical thinking. Creative thinking is often understood as that big 'ah ha!' moment when a new idea suddenly transforms how something is understood or done. But creative thinking can also be a learned process (DeHaan, 2009). In this form (something DeHaan denotes as 'small c' creativity) it can be more incremental and emergent as it is combined with other ways of thinking scientifically. Impact in science often derives from conventional thinking combined or applied in new ways (Uzzi, Mukherjee, Stringer, \& Jones, 2013). Challenging some of the assumptions about what creative thinking is and how it is done is the first stage of learning creative thinking skills. 
Similarly, reflective thinking is equally important in science. The journals of famous scientists (e.g. Marie Curie, Joseph Banks) model the value of reflective thinking. Critical reflection underpins critical thinking (Mezirow, 1910). However, as with creative thinking, reflective practice is often assumed to be something that is not deliberate or learned. Reflective thinking is often learned in a superficial way because it is not purposefully scaffolded into a curriculum (Ryan \& Ryan, 2012).

Learning ethical thinking is critical in the Science Learning and Teaching Academic Standards Threshold Learning Outcomes for Australian science teaching in higher education (Jones, Yates, \& Kelder, 2011). In science, ethical practice has many layers. At a basic level it is about things like accurately recording and storing data, intellectual integrity, aligning practice with animal and human ethics requirements. But scientists must also respond to social and cultural nuances in their bid to understand the natural world. This requires interpersonal and reflective skills to apply ethical practice.

Even less acknowledgement is given to the importance of emotional thinking in scientific thinking. In fact, emotional thinking is seen to detract from high-quality scientific thinking. The impact of emotions on bias in thinking certainly needs to be controlled for in critical thinking (Martel, Pennycook, \& Rand, 2020). However, science that has impact (i.e. changes how we function and understand the world) can't be abstracted from the human setting it must be integrated into. To do so relegates it to the theoretical academic literature where it remains isolated from the society it is intended to benefit (Jones, McGarrah, \& Kahn, 2019). Emotional thinking is also critical in learning science for the teacher (Zembylas, 2004) and the student (Mezirow, 1991).

It is the combination of all these different types of scientific thinking that determines the quality of science practice (McBain et al., 2019). Therefore, science students require foundational learning in each to become high-quality scientists.

\section{A Scientific Thinking unit at the University of Newcastle}

\section{Context - revision of the Bachelor of Science}

In 2017 the University of Newcastle undertook a 'roots and branches' review of its Bachelor of Science (BSc). The strategic planning for the revision was undertaken via a highly collaborative 6-month process. It involved over 200 stakeholders from various groups including science or STEM: 1) academic teaching staff; 2) professional and technical staff, 3) current undergraduate students 4) post-graduate students, 5) prospective university students (school students attending a 'Science Fest' day), 6) industry, 7) UoN staff from other faculties, 8) UoN STEMM leaders, 9) staff with transferrable skills expertise and 10) pedagogy experts.

This led to a mandate for 1) teaching how to think scientifically, 2) connecting the student learning journey, 3) explicitly teaching transferrable skills, 4) embedding sustainability, 5) employability/WIL, 6) more-than-single disciplinary practice, and 7) entrepreneurialism.

Six new core subjects (see Figure 1) were to do the 'heavy lifting' for this mandate with consolidation occurring within the disciplinary study elsewhere in the degree (disciplinary Majors, Minors and elective pathways). 


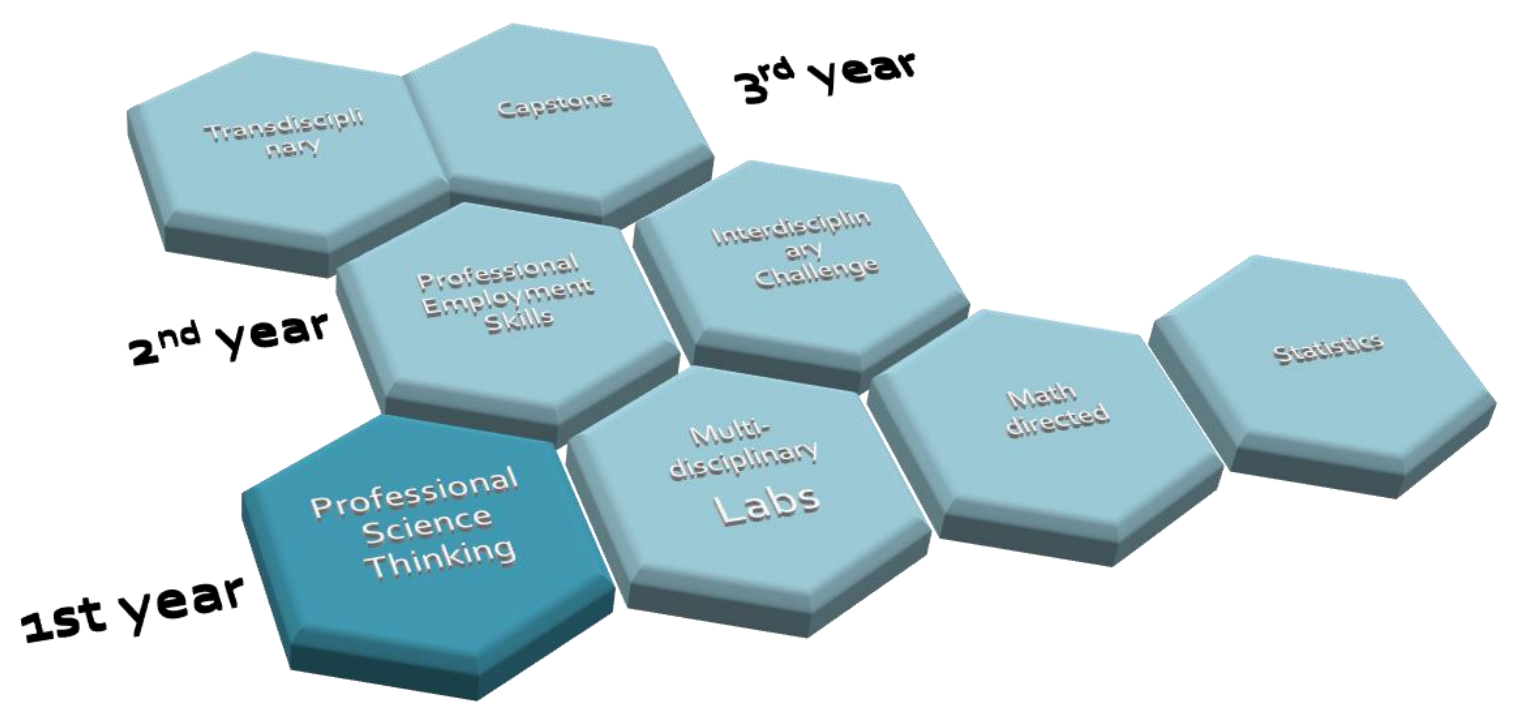

Figure 1. The new core subjects in the BSc at the University of Newcastle

\section{First year core subject - Professional Scientific Thinking}

The focus of the first-year core subject called 'Professional Scientific Thinking is how to think like, and be, a high-quality scientist. This subject provides a foundational learning about the different ways that scientists think, including critical, creative, reflective and ethical (McBain et al., 2019). Students learn how each type of thinking is critical for high-quality science. The curriculum challenges some of the assumptions commonly made about different types of thinking (e.g. creative thinking is inborn and can't be learned)

To ensure that the subject materials are applied, students connect the online subject content with practical workshop activities where active learning (Wieman, 2017) demonstrates elements of different types of thinking. The curriculum is made 'real' through examples from history, from current popular science, and examples from the lived experiences of tutors leading the workshop activities. This helps students learn about the research that is undertaken at their own institution and shows how high-quality science is embodied by a real, practicing scientist.

This subject is blended or flipped in response to the highly diverse student cohort. Nearly half of students are mature aged and a third are from a lower socio-economic background with significant work and family responsibilities. In consultations with current students whilst revising the BSc, students told us that the reason they did not often come to lectures was that they needed to work in order to be able to study. These students needed flexibility in their study (the online component of the subject can be studied at any time during the week before the interactive workshops). The constructive alignment (Wang, Su, Cheung, Wong, \& Kwong, 2013) of online subject materials with the workshop activities and assessment tasks was intended to emphasise the relevance and importance of engaging with the online material.

The four critical learning outcomes for students are:

- what high quality science is

- how to identify poor science and non-science

- how to become a scientist who practices high quality science and

- to develop foundational science writing skills 
The subject demonstrates the various ways to think scientifically by identifying the practices of high-quality science (through the scientific method) and contrasting that with poor science and non-science (pseudoscience). Both the online subject content and the workshops are embedded into a pedagogy that supports active learning (Partridge et al., 2001; Wieman, 2017), constructive alignment (Wang et al., 2013) and aligns with best practice blended learning (Stone, 2017).

\section{Connections with subsequent learning}

This paper discusses a small range of different types of scientific thinking that first year students need to be aware of. However, this paper cannot address the full range of thinking skills required. In our connected curriculum across years one to three, the foundational skills noted here are applied via project-based learning. This project-based learning also adds a range of other scientific thinking skills required by scientists such as entrepreneurial thinking (Robinson, Stimpson, Huefner, \& Hunt, 1991), design thinking (Anderson et al., 2014), systems thinking (Meadows, 2008), complexity thinking (Brown, 2010) etc. The subject that we document here is the foundational exposure that allows students to apply these other types of scientific thinking.

\section{Data Collection}

Five types of data were collected to evaluate the student experience, engagement and the learning outcomes from the first-year subject:

1. the University of Newcastle routinely collects student feedback on subjects via fifteen questions (Student Feedback on Courses, SFCs).

2. University of Newcastle data on student success (pass rates) and attrition (after census date) for a range of student demographic groups.

3. Brookfield's Critical Incident Questionnaire (CIQ) (1995) in Week 5 of the subject. The questionnaire asks five open ended questions of students about their experience of doing a subject. The approach is powerful in identifying student lead perspectives because open ended questions don't constrain what students can report. Analytics were collected for student engagement with online modules of subject content each week.

4. student success for individual lines of a grading rubrics for an assessment requiring written communication (a Nobel Prize nomination for an admired scientist).

5. a focus group session undertaken with two students and run by an independent facilitator.

\section{Evaluation}

Students rated the relevance of the subject as high in their Student Feedback on Courses (3.92 out of 5) in its first offering. It is difficult to disaggregate student feedback scores and hence it is not possible, from this data, to identify the reasons underlying these relatively high student satisfaction scores (likely it is a combination of things). Brookfield's Critical Incident Questionnaire (CIQ) (1995) allowed us to identify the reasons directly from students. Most students doing SCIE1001 $(83 \%, \mathrm{n}=59)$ reported that the three most engaging elements of the subject were:

1. content helping them identify high-quality science,

2. the engaging assessments, and

3. the carefully curated online explanatory videos. 
The collaborative student learning in face-to-face workshops was also most motivating for $42 \%$ of students: 'discussing the assessment task with peers provided useful feedback on how to link content from the workshops into the assessment'.

A key learning outcome in SCIE1001 is to be able to identify the practices of high-quality scientists. Students write a Nobel Prize nomination of their favourite scientist (due Week 6). This requires them to integrate online subject content from Weeks $1-6$. Figure 2 shows that the constructive alignment (Wang et al., 2013) of 1) learning outcomes, 2) online subject material and 3) the assessment successfully engages students with online materials from previous weeks (total student interactions with the online material and the number of modules accessed increases). As the subject progresses and students prepare their first assessment, they not only review the online subject materials for the week they are in, but also review previous weeks' subject materials. The use of online subject modules peaks in Week 6 when the assessment is due as students 'analyse' and 'apply' (Anderson, Krathwohl, \& Bloom, 2001) what they have learned from the subject to date (i.e. Weeks 1 - 6 inclusive).

Student feedback indicates that the approach to teaching and the subject content can have a profound effect on students' perception of their future career. For example: 'In the beginning I loathed this class. Felt like I performed the pre class work only to re explain it to my "peers" who hadn't bothered. However, by the end I felt that I had learned a great deal about how I wish to continue my future career and I felt more fulfilled than most of my classes have ever left me' (SFCs, 2019). Similarly: 'Most of my classes I learn material and it's as simple as that but this class I felt helped me grow as both a person and an academic and I am very grateful to have been part of the class' (SFCs, 2019).

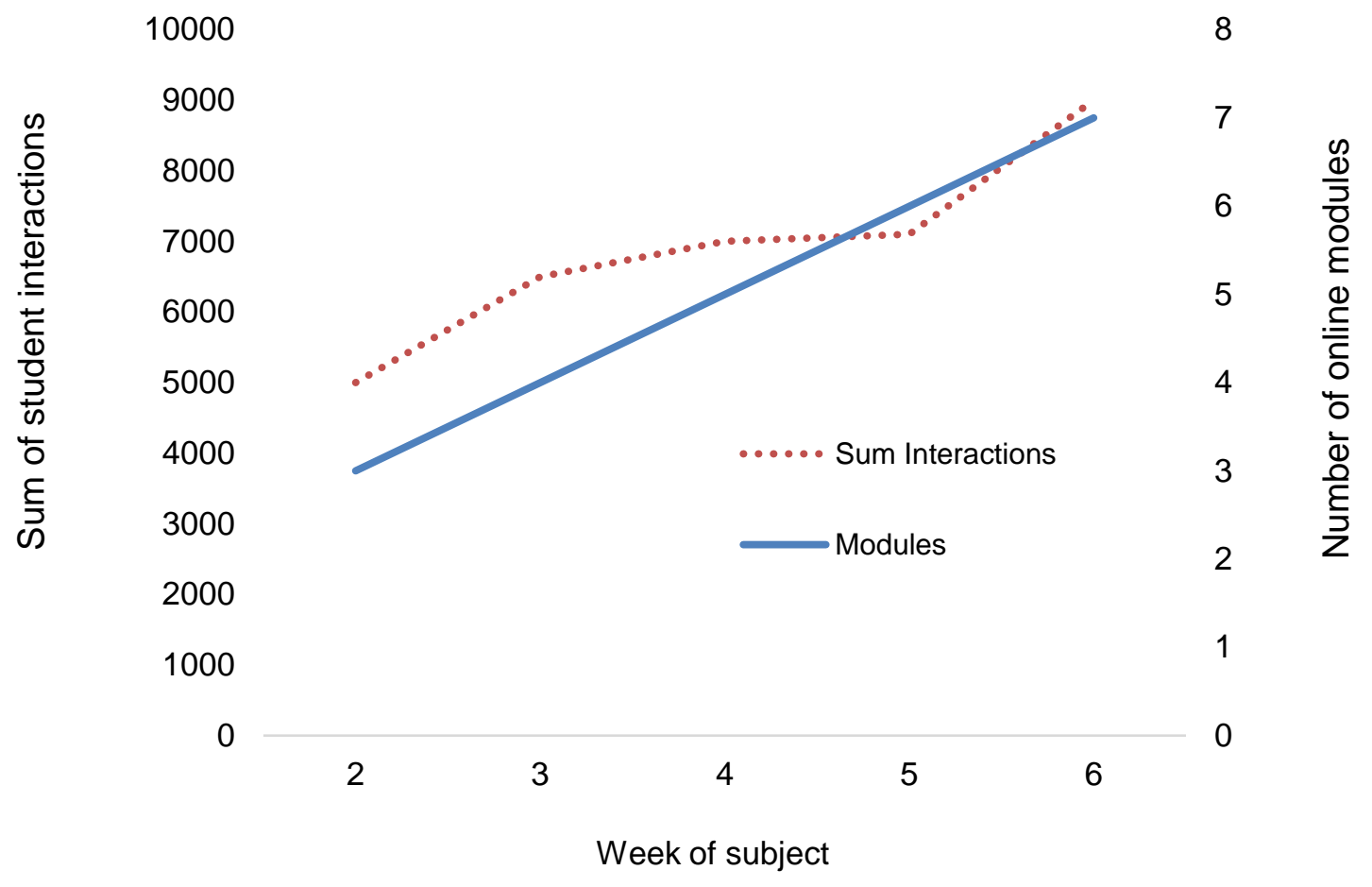

Figure 2. Analytics from online subject content measuring student engagement each week. The assessment task was due in Week 6. 
Aboriginal and Torres Strait Islander students showed equivalent or higher success (a pass or higher) than non-Indigenous students (85-93\% compared to $80 \%$ ). Students from high, medium or low socioeconomic status also had high levels of success (average of $88 \%, 84 \%$ and $77 \%$, respectively) and low withdrawal $(5 \%, 7 \%, 7 \%$, respectively). Success or retention were equivalent for students from a range of admission levels (from higher education, from secondary education and from the VET sector). Only mature-aged students had a pass rate 8\% lower than the average, triggering more targeted investigations about how to better support these students in the next iteration of the subject.

A key learning outcome of the subject is to develop strong academic writing skills due to its strong links with scientific thinking skills (Dowd, Thompson, Schiff, \& Reynolds, 2018). There is significant investment in learning materials to guide students in how to write a strong argument in the Nobel Prize nomination assessment task. Analysis of the individual lines of the marking rubric was undertaken to measure how many students attained the key elements of high-quality writing. Table 1 shows that $98 \%$ of students adequately demonstrated key writing skills (a Pass grade or higher) and 60-70\% attained highly developed skills in writing (attained a Distinction or higher).

Table 1. The percentage of students who attained a particular standard (grade) for various elements of writing in the Nobel Prize nomination assessment task.

\begin{tabular}{|l|r|r|l|l|l|r|}
\hline & $\begin{array}{l}\text { Explanation } \\
\text { of topic in } \\
\text { middle of } \\
\text { paragraph }\end{array}$ & $\begin{array}{l}\text { Distinct } \\
\text { topic in each } \\
\text { paragraph }\end{array}$ & $\begin{array}{l}\text { Last sentence } \\
\text { summarises } \\
\text { paragraph } \\
\text { idea }\end{array}$ & $\begin{array}{l}\text { Similar } \\
\text { paragraph } \\
\text { sizes }\end{array}$ & $\begin{array}{l}\text { Cohesion } \\
\text { between } \\
\text { paragraphs }\end{array}$ & $\begin{array}{l}\text { Appropriate } \\
\text { word choice }\end{array}$ \\
\hline HD & $19 \%$ & $27 \%$ & $19 \%$ & $25 \%$ & $23 \%$ & $25 \%$ \\
\hline D & $44 \%$ & $41 \%$ & $42 \%$ & $45 \%$ & $41 \%$ & $41 \%$ \\
\hline C & $32 \%$ & $27 \%$ & $30 \%$ & $23 \%$ & $29 \%$ & $28 \%$ \\
\hline P & $4 \%$ & $5 \%$ & $7 \%$ & $7 \%$ & $6 \%$ & $6 \%$ \\
\hline F & $1 \%$ & $1 \%$ & $2 \%$ & $1 \%$ & $2 \%$ & $0 \%$ \\
\hline
\end{tabular}

Students could also identify the relevance of subject content in the inquiry-based learning (Zimbardi et al., 2013) they were undertaking in the complementary first year core subject SCIE1002 Multidisciplinary Laboratories. For instance, feedback from students in the focus group discussions indicates that 'the [two first year core] subjects support each other, cross overs are helpful rather than repetitive, and learning in one is often applied in the other'. This is particularly critical, as the relevance of learning must be linked to practice if it is to be of value in an applied discipline such as science (Gottersman \& Hoskins, 2017).

\section{Implications for best practice science teaching}

Both the literature (Dowd et al., 2018; Gottersman \& Hoskins, 2017; Rowe et al., 2015; Zimbardi et al., 2018) and the evaluation of this subject indicate that subjects in which students are taught about high quality scientific thinking and scientific practice can successfully engage and support students' learning if:

- the relevance of the subject content is clearly articulated, and high expectations are set

- constructive alignment of subject learning outcomes, subject materials and assessment tasks occurs

- a high quality, evidence-based curriculum and pedagogy support a range of students from different backgrounds 
- active, participatory learning helps to engage students in their learning, making it more relevant and meaningful to them as individuals

- high quality learning resources that engage students with their learning in a way that's both interesting, fun and connected to practice are curated by educators

\section{Conclusion}

The use of a range of scientific thinking skills, which can all be learned, is critical for high quality scientific practice across all scientific disciplines. Students completing these subjects valued the learning in the subject and thought it relevant. An understanding of what high quality science is, knowing about the diverse ways to think scientifically and foundational writing skills can be successfully demonstrated by first year BSc students. Rates of academic success were high across the cohort and were equivalent for groups of students across all but one of the recognised equity groups. High quality learning outcomes have been achieved through embedding an evidence-based pedagogy for best practice science education - active learning, participatory learning, student-centred learning, constructive alignment and quality formative and summative feedback to students. This outcome is consistent with others' findings reported in the literature.

\section{References}

Anderson, N., Adam, R., Taylor, P., Madden, D., Melles, G., Kuek, C., . . Ewens, B. (2014). Design thinking frameworks as transformative cross-disciplinary pedagogy. Retrieved from Canberra, Australia: https://eprints.qut.edu.au/82004/1/Anderson\%20SD12_2552_Report_2014.pdf

Anderson, L. W., Krathwohl, D. R., \& Bloom, B. S. (2001). A taxonomy for learning, teaching, and assessing: A revision of Bloom's taxonomy of educational objectives: Allyn \& Bacon.

Barz, D. L., \& Achimas-Cadariu, A. (2015). The development of scientific reasoing in medical education: a psychological perspective. Medical Education, 89(1), 32-37. doi:10.15386/cjmed-530

Brookfield, S. (1995). Becoming a Critically Reflective Teacher. Jossey-Bass, San Francisco.

Brown, V. A. (2010). Collective inquiry and its wicked problems. In V. A. Brown, J. A. Harris, \& J. Y. Russell (Eds.), Tackling wicked problems through the transdisciplinary imagination (pp. 61-83). London and Washington D.C. : Earthscan.

Chalmers, A. (2014). What is this thing called science? 4th Edition, Hackett Publishing Inc: Indianapolis: USA

DeHaan, R. L. (2009). Teaching creativity and inventive problem solving in science, Life Sciences Education, 8 (Fall 2009), pp. 172-181.

DeloittCae Access Economics. (2014). Australia's STEM workforce: a survey of employers. Retrieved from Australia: https://www2.deloitte.com/au/en/pages/economics/articles/australias-stem-workforce-survey.html

Dowd, J. E., Thompson, R. J., Schiff, L. A., \& Reynolds, J. A. (2018). Understanding the complex relationship between critical thinking and science reasoning among undergraduate thesis writers. CBS Life Sciences Education, 17(1). doi:10.1187/cbe.17-03-0052

Dunbar, K. N., \& Fugelsang, J. A. (2005). Causal Thinking in Science: How Scientists and Students Interpret the Unexpected. In M. E. Gorman, R. D. Tweney, D. C. Gooding, \& A. P. Kincannon (Eds.), Scientific and technological thinking (p. 57-79). Lawrence Erlbaum Associates Publishers.

Dunning, D. (2011). The Dunning-Kruger Effect: On Being Ignorant of One's Own Ignorance. In: Advances in Experimental Social Psychology. Editor(s): James M. Olson, Mark P. Zanna, Academic Press, Volume 44, pp. 247-296, https://doi.org/10.1016/B978-0-12-385522-0.00005-6.Fidler, F., Fraser, H. . (2018). Our survey found 'questionable research practices' by ecologists and biologists - here's what that means. The Conversation, April 10.

Fidler, F. \& Gordon, A. (2013). Science is in a reproducibility crisis - how do we resolve it? The Conversation, September 20.

Gibbs, G. (1988). Learning by Doing: a guide to teaching and learning methods. Oxford Further Education Unit, Oxford Polytechnic: Oxford.

Gottersman, A. J., \& Hoskins, S. G. (2017). CREATE Cornerstone: Introduction to Scientific Thinking, a New Course for STEM-Interested Freshmen, Demystifies Scientific Thinking Through Analysis of Scientific Literature. Life Sciences Education, 12(1). doi:doi.org/10.1187/cbe.12-11-0201

Holyoak, K. J. \& Morrison, R. G. (2005). The Cambridge handbook of thinking and reasoning. Cambridge University Press: Cambridge. 
Impey, C., Buxner, S., Antonellis, J., Johnson, E., \& King, C. (2011). A Twenty-Year Survey of Science Literacy Among College Undergraduates. Journal of college science teaching, 40(4).

Johnson, E. (2014). Changing the game in science and mathematics higher education - changing the game: A national approach to learning and teaching for science and mathematics. Australian Government Office for Learning and Teaching, Australian Council of Deans of Science and LaTrobe University. Retrieved from: https://altf.org/wp-content/uploads/2016/08/Johnson_E_NTF_report_2014.pdf

Jones, S., Yates, B., \& Kelder, J.A. (2011) Science: Learning and Teaching Academic Standards Statement. http://www.acds-tlcc.edu.au/wp-content/uploads/sites/14/2016/11/altc_standards_SCIENCE_240811_v31.pdf

Jones, S. M., McGarrah, M. W., \& Kahn, J. (2019). Social and emotional learning: A principled science of human development in context. Educational Psychologist, 54(3), 129-143.

Kahneman, D. (2011). Thinking, fast and slow. New York: Farrar: Straus and Giroux.

Kirkup, L., \& Johnson, L. (2013). Science good practice guide - threshold learning outcome 3 - inquiry and problem-solving. Retrieved from Canberra, Australia: http://www.acds-tlcc.edu.au/wpcontent/uploads/sites/14/2013/01/Science-Good-Practice-Guide-2013_FINAL-TLO3.pdf

Lackeus, M. (2015). Entrepreneurship in education - what, why, when, how. Background paper.

Lagnado, D. A. (2011). Causal thinking. In Editor(s): Phyllis Illari, Federica Russo, Jon Williamson, Causality in the sciences, (pp. 129-149). New York, Oxford University Press.

Marginson, S., Tytler, R., Freeman, B., \& Roberts, K. (2013). STEM: country comparisons: international comparisons of science, technology, engineering and mathematics (STEM) education. Retrieved from Melbourne, Victoria.: http://hdl.handle.net/10536/DRO/DU:30059041

Martel, C., Pennycook, G., \& Rand, D. G. (2020). Reliance on emotion promotes belief in fake news. Cognitive research: principles and implications, 5(1), 1-20.

McBain, B., Yardy, A., Martin, F., Tose, H., Phelan, L., van Altena, I., . . Bowyer, M. (2019, 2 - 4 October 2019. Avoiding the science stupidity trap. Paper presented at the Proceedings of the Australian Conference on Science and Mathematics Education, The University of Sydney and University of Technology

McInnis, C., Hartley, R., \& Anderson, M. (2000). What did you do with your science degree? A national study of employment outcomes for science degree holders 1990-2000. Retrieved from Melbourne, Australia: https://melbourne-cshe.unimelb.edu.au/_data/assets/pdf_file/0005/1494716/ScienceR.pdf

Meadows, D. H. (2008). Thinking in systems. White River Junction, USA: Chelsea Green Publishing Co.

Mezirow, J. (1990). How critical reflection triggers transformative learning. Fostering critical reflection in adulthood, 1(20), 1-6.

Mezirow, J. (1991). Transformative dimensions of adult learning. San Francisco: Jossey-Bass.

Partridge et al., 2001: Partridge, H., Ponting, D., \& McCay, M. (2001). Good practice report - blended learning. Canberra, Australia: Australian Learning and Teaching Council. url: https://www.researchgate.net/publication/279662798_Good_Practice_Report_Blended_Learning

Rittel, H.W.J. \& Webber, M.M. (1973). Dilemmas in a General Theory of Planning. Policy Sciences, 4, 155-169

Robinson, P. B., Stimpson, D. V., Huefner, J. C., \& Hunt, H. K. (1991). An Attitude Approach to the Prediction of Entrepreneurship. Entrepreneurship Theory and Practice, 15(4), 13-32. doi:10.1177/104225879101500405

Rowe, M. P., Gillespie, B. M., Harris, K. R., Koether, S. D., Shannon, L.-J. Y., \& Rose, L. A. (2015). Redesigning a general education science course to promote critical thinking. CBE-Life Sciences Education, 14(3), ar30.

Ryan, M., \& Ryan, M. (2012). Developing a systematic, cross-faculty approach to teaching and assessing reflection in higher education. Retrieved from Canberra, Australia: https://research.qut.edu.au/eportfolio/wpcontent/uploads/sites/186/2018/03/ALTC_Final_Report_Part_1_PP9-1327.pdf

Stone, C. (2017). National Guidelines: opportunity through online learning - improving student access, participation and success in higher education. NCSEHE, Curtin University \& The University of Newcastle. url: https://www.ncsehe.edu.au/publications/opportunity-online-learning-improving-student-accessparticipation-success-higher-education/

Uzzi, B., Mukherjee, S., Stringer, M., \& Jones, B. (2013). Atypical combinations and scientific impact. Science, 342(6157), 468-472.

Wang, X., Su, Y., Cheung, S., Wong, E., \& Kwong, T. (2013). An exploration of Biggs' constructive alignment in course design and its impact on students' learning approaches. Assessment \& Evaluation in Higher Education, 38(4), 477-491, doi:10.1080/02602938.2012.658018.

Wieman, C. (2017). Improving how universities teach science: lessons from the science education initiative: Harvard University Press.

Zimbardi, K., Bugarcic, A., Colthorpe, K., Good, J. P., \& Lluka, L. J. (2013). A set of vertically integreated inquiry-based practical curricula that develop scientific thinking skills for large cohorts of undergraduate students. Advanced Physiology Education, 37, 303-315, doi:10.1152/advan.00082.2012. 